\title{
A democracia e a questão urbana na constituinte brasileira (1987-1988)
}

\author{
Democracy and the urban issue in the Brazilian \\ constituent (1987-1988)
}

Ana Paula Koury [a] [D], Bruno Santana de Oliveira [a] [D]

Como citar: Koury, A. P., \& Oliveira, B. S. (2021). A democracia e a questão urbana na constituinte brasileira (1987-1988). urbe. Revista Brasileira de Gestão Urbana, v. 13, e20200007. https://doi.org/10.1590/2175-3369.013.e20200007

\section{Resumo}

O artigo apresenta os resultados da leitura, sistematização e análise das atas da Subcomissão da Questão Urbana e de Transporte da Assembleia Nacional Constituinte (1987-1988). A pesquisa identificou as instituições que foram chamadas ao debate, o momento em que foram incluídas no debate, e o setor social representado, os profissionais liberais, as empresas estatais, setores ligados ao mercado imobiliário, os intelectuais e os movimentos sociais urbanos. 0 objetivo da pesquisa foi percorrer o debate em torno da questão urbana na Constituinte de 1987-1988 em busca de explicitar a posição das instituições que foram incluídas no debate. Quais eram as suas propostas? Como o consenso sobre a questão urbana foi construído na Subcomissão? Considerando que esse foi o marco da transição democrática em uma sociedade altamente urbanizada, acreditamos que os elementos dessa investigação possam contribuir ao debate sobre a democracia urbana brasileira e a sua crise institucional no período recente.

Palavras-chave: Reforma Urbana. Política Urbana. Constituinte de 1987.

\section{Abstract}

The paper presents the results of reading, systematizing and analyzing the minutes of the Subcommittee on Urban Issues and Transport of the National Constituent Assembly (1987-1988). The research identified the institutions that were called to the debate, the moment when they were included in the debate, and the social sector represented, the professionals, the state companies, sectors linked to the real estate market, the intellectuals and the urban social movements. The objective of the research was to go through the debate around the urban issue in the 1987-1988 Constituent in order to explain the position of the institutions that were included in the debate. What were your proposals? How was the consensus on the urban issue built in the Subcommittee? Considering that this was the landmark of the democratic transition in a highly urbanized society, we believe that the elements of this investigation can contribute to the debate about Brazilian urban democracy and its recently institutional crisis.

Keywords: Urban Reform. Urban Politics. 1987 Constituent Assembly. 


\section{Introdução}

Em 2018 a chamada Constituição Cidadã de 1988 completou trinta anos. A efeméride ocorreu em meio à crise do Estado Brasileiro deflagrada pelo impeachment da presidente Dilma Rousseff e pela prisão do expresidente Luiz Inácio Lula da Silva, que liderava as pesquisas de opinião como principal candidato à presidência da República. A derrota do Partido dos Trabalhadores (PT) nas eleições do mesmo ano foi acompanhada pela ascensão política da extrema direita que saiu vitoriosa do pleito. Nesse processo, o sistema judiciário brasileiro ocupou o centro de decisão da vida política do país. Isso ocorreu ao mesmo tempo em que os direitos civis constitucionais eram o alvo preferido do discurso radical de direita. Nesse quadro, a Constituição de 1988 foi inúmeras vezes evocada em defesa da democracia Brasileira.

A Constituição de 1988 definiu os princípios da política urbana brasileira posteriormente desenvolvidos no Estatuto da Cidade (Lei Federal no 10.257, de 10 de julho de 2001) (Brasil, 2001). Na época em que a Constituição foi aprovada, o país atingia 75\% da população total concentrada em cidades, $41 \%$ da população vivendo em situação de pobreza (53.2 milhões de pessoas) e ainda 55\% delas vivendo nas cidades sendo que 18\% concentravam-se nas regiões metropolitanas (Santagada, 1990, p. 121-143).

A rápida e concentrada urbanização brasileira ocorreu principalmente pelo êxodo rural das populações das regiões mais pobres do país, principalmente do Nordeste, em direção ao Sudeste industrializado, indicando a dimensão regional da desigualdade no Brasil e suas consequências sobre a disputa em torno da questão fundiária urbana. As periferias das grandes cidades brasileiras abrigaram a maior parte do contingente de migrantes, que reproduziram nesses espaços urbanos uma forma específica de subsistência material e cultural em meio à pobreza, como registrado por Kowarick \& Brant (1976), Kowarick (1988) entre outros autores. Na década de oitenta, os movimentos sociais urbanos emergiram como uma força social organizada em luta pela superação da desigualdade no acesso à cidade formal (Santos, 1981; Jacobi, 1989). Foi nesse quadro de ascensão dos movimentos sociais organizados que a questão urbana foi incluída na agenda da Assembleia Constituinte de 1988 (Brasil, 1987a).

A política urbana e a moradia foram amplamente debatidas na Subcomissão da Questão Urbana e Transportes da Constituição Federal de 1988, cujas atas foram registradas no Diário da Assembleia Nacional Constituinte (Brasil, 1987b, 1987c, 1987d, 1987e, 1987f, 1987g, 1987h, 1987i, 1987j, 1987k). O texto final da Constituição dedicou uma sessão específica para a política urbana que reconheceu "a função social da propriedade" regulamentada pelos planos diretores municipais, obrigatórios para as cidades com mais de 20.000 habitantes, e também os instrumentos da reforma urbana, como o Parcelamento e Edificação Compulsório (PEUC), o Imposto Predial e Territorial Urbano (IPTU) progressivo, e a possibilidade de desapropriação com pagamento através de títulos da dívida pública (Brasil, 1988b).

A inclusão da política urbana na Constituição de 1988 e, posteriormente, a aprovação do Estatuto da Cidade em 2001 significou, para toda uma geração de ativistas engajados com a questão urbana no Brasil, uma vitória estratégica em direção a uma sociedade urbana mais inclusiva e democrática. Permitiu incluir, no marco legal do país, os instrumentos da reforma urbana que estavam sendo propostos pelos arquitetos desde o Seminário de Habitação e Reforma Urbana de 1963 (Bonduki \& Koury, 2010; Koury, 2013).

Mas quem foram os agentes incluídos no debate do marco regulatório? Como foi construído o acordo sobre a cidade na antessala da Constituição de 1988? Este artigo apresenta os resultados da pesquisa realizada nas atas da Subcomissão da Questão Urbana e Transportes. Os procedimentos metodológicos adotados para a pesquisa foram, em primeiro lugar, a localização das atas e sistematização das reuniões por temas tratados. Em seguida foram selecionadas para a leitura as atas das reuniões em que os temas da política urbana, inclusive moradia e mobilidade urbana, foram abordados. Nas atas dessas reuniões identificamos as instituições convocadas, os seus representantes e as propostas apresentadas. 0 material foi disposto em tabelas e permitiu conhecer as diferentes propostas que estiveram em debate na Subcomissão. Após a leitura das atas, comparamos as propostas debatidas com aquelas incluídas nos Anteprojetos do Relator e da Subcomissão, com o objetivo de identificar quais propostas haviam sido incluídas nesses relatórios. Finalmente, os relatórios foram comparados com o capítulo 2 da Política Urbana 
da CF de 1988. Por meio do material analisado, foi possível concluir que diferentes setores sociais confrontaram-se durante as reuniões e que o texto Constitucional representa uma parte desse debate. Mas, afinal, que parte é essa?

0 texto está dividido em cinco itens. No primeiro "A democracia e a reforma urbana" apresentamos o funcionamento da Assembleia Constituinte e os debates sobre a reforma urbana e sobre os marcos legais da política urbana. No segundo item "A Subcomissão da Questão Urbana e Transportes na Constituinte (1987)" explicamos o funcionamento da Subcomissão, a organização dos trabalhos e o calendário das reuniões com os temas principais abordados em cada uma das reuniões. No terceiro item "A política urbana em debate na Subcomissão" apresentamos as propostas para política urbana que foram levadas pelas instituições convidadas para as audiências públicas e o resultado final dos trabalhos da Subcomissão o "Anteprojeto da Subcomissão". No quarto item "O setor privado no centro de uma nova política habitacional" apresentamos as propostas do setor privado para uma nova política habitacional. Para esses setores a questão social justificaria um programa de fomento centrado na oferta de unidades pela indústria da construção. Nesse sentido, "o social" não representava conflitos ou contradições de classe. No último item, a título de conclusão, consideramos que o "Anteprojeto da Subcomissão" representa os acordos sociais vigentes na produção material da cidade, explicando de certa forma o limitado alcance que os instrumentos redistributivos obtiveram na prática da política urbana.

\section{A democracia e a Reforma Urbana}

O regimento interno da Assembleia Constituinte abriu muitos canais para que a sociedade civil organizada participasse da construção da democracia brasileira. Representantes de setores da sociedade civil foram convidados para participar das reuniões das comissões e subcomissões. Várias entidades puderam apresentar propostas concretas para os constituintes e foi permitido à inciativa popular encaminhar emendas diretamente à Comissão sistematizadora e defendê-las no plenário da assembleia. As propostas deveriam ter no mínimo o apoio de 30 mil eleitores e serem encaminhadas por três entidades legalmente constituídas. Essa foi uma oportunidade para a formação de uma frente em defesa da Reforma Urbana. O Movimento Nacional pela Reforma Urbana (MNRU) teve uma abrangência nacional e reuniu profissionais liberais, principalmente os arquitetos, engenheiros e advogados, e também setores ligados à igreja e aos movimentos sociais urbanos. Bonduki (2018, p. 98-99) relata que o MNRU se reuniu pela primeira vez em 5 de maio de 1987 quando 63 entidades debateram em doze horas a proposta que seria apresentada no dia seguinte na 15a Reunião ordinária da Subcomissão da Questão Urbana e Transportes. Mais tarde, em 19 de agosto de 1987, essa proposta seria apresentada em forma de emenda popular à Comissão Sistematizadora, subscrita por 131 mil eleitores e encaminhada pelo Instituto de Arquitetos do Brasil (IAB), Federação Nacional de Arquitetos (FNA) e Federação Nacional de Engenheiros (FNE). Foi identificada como Emenda Popular n. 63 que dispõe sobre a Reforma Urbana (Brasil, 1988a).

Coube a Bonduki pelo Sindicato dos Arquitetos de São Paulo, Franklin Coelho pelo Sindicato dos Engenheiros do Rio de Janeiro, Flora Eujace Maranhão pela Articulação Nacional do Solo Urbano, entre outros representantes dos movimentos sociais urbanos organizados, apresentar a proposta do MNRU na reunião da Subcomissão em 6 de maio de 1987 e foi Ermínia Maricato quem fez a defesa no plenário da Assembleia em novembro do mesmo ano. Como afirma Bonduki (2018, p. 103-105) a emenda não apresentou grandes inovações em relação aos instrumentos urbanísticos da Reforma Urbana presentes no Projeto de Lei 775 de 1983, mas avançou na representação popular incluindo as reivindicações dos movimentos sociais urbanos e a gestão democrática das cidades (Brasil, 1983).

O capítulo sobre a política urbana na Constituição Federal de 1988 e posteriormente o Estatuto da cidade foram interpretados pela maioria dos autores como a evolução histórica da agenda da Reforma Urbana, incluída no debate político nacional com o Seminário de Habitação e Reforma Urbana realizado em 1963 (Bassul, 2002; Quinto Jr, 2003; Bonduki \& Koury, 2010; Bonduki, 2018). Foi nessa época, durante o governo de João Goulart, que os arquitetos introduziram a questão urbana nas amplas discussões sobre as 
reformas de base. Um dos resultados do Seminário de 1963 foi a sugestão de instrumentos constitucionais para restringir o direito de propriedade privada do solo urbano.

Trabalhos como os de Rolnik (1994); Cardoso (1997); Maricato (2014); Bonduki (2018) avaliaram criticamente a incorporação da emenda popular pela Reforma Urbana no texto constitucional e a inclusão dos planos diretores como instrumentos de controle da função social da propriedade. Quinto Jr. (2003, p. 193) apontou a presença de representantes do mercado imobiliário na Subcomissão da Questão Urbana e Transportes, dando visibilidade ao acompanhamento crítico das atividades da Subcomissão que foi realizado pela Universidade de Brasília e pela Federação Nacional dos Arquitetos. Quinto Jr. afirma que "os lobbies do mercado imobiliário dominam a Subcomissão da Política Urbana e Transportes" e menciona a presença do empresário Sergio Naia e do deputado Sérgio Nahas, ambos ligados ao setor empresarial imobiliário.

Entretanto, poucos autores apresentaram, em uma perspectiva histórico-crítica, a disputa política em torno das narrativas da Reforma Urbana no Brasil. Depois no MNRU, o tema da Reforma Urbana e sua origem histórica ficou associado ao projeto democrático popular com base nos movimentos sociais urbanos que emergiu nos anos oitenta. Francisconi (2013) foi um dos poucos autores a questionar a linha evolutiva da história da Reforma Urbana, ressaltando as diferenças entre a agenda em 1963 e aquela que dominaria nas décadas seguintes.

O campo da democracia popular com base nos movimentos sociais urbanos, que se organizou durante a redemocratização, foi liderado pelos arquitetos que reivindicam um lugar destacado na institucionalização da política urbana pela Constituição de 1988 e depois pelo Estatuto da Cidade, Lei Federal. 0 Estatuto da Cidade procurou garantir a gestão democrática das cidades e, com isso, universalizar o acesso a condições básicas de moradia e serviços urbanos como saneamento, transporte, educação e saúde, com o objetivo de atender principalmente a população trabalhadora, pobre e urbanizada em condição precária nos grandes centros urbanos. 0 que foi, sem dúvida, um marco na afirmação dos direitos urbanos dos trabalhadores, colocado em prática por algumas experiências inovadoras em administrações municipais na década de noventa. A luta política em torno do direito à cidade consolidou nesse período uma importante base eleitoral, que contribuiu para a vitória do Partido dos Trabalhadores (PT), no pleito presidencial do ano seguinte à aprovação do Estatuto. Esse foi o quadro político que antecedeu a criação do Ministério das Cidades em 2003, e que originou um curto período em que a instituição foi liderada por quadros políticos comprometidos com a agenda da Reforma Urbana e dos movimentos sociais urbanos.

Mais de uma década separa a Constituição de 1988 e a aprovação do Estatuto da Cidade em 2001. 0 longo processo de proposição, tramitação e aprovação da lei federal de 2001 foi registrado por Grazia (2002) e explicita a luta em torno de um projeto político redistributivo de base urbana no qual engajou-se toda uma geração de profissionais, técnicos e intelectuais. Por outro lado, a análise das atas das reuniões, apresentada neste artigo, evidencia o complexo jogo político no qual prevalecem as contribuições das instituições burocráticas em prejuízo da participação direta dos movimentos sociais urbanos, que já se encontravam organizados naquela época. Apesar disso, os principais mecanismos da reforma urbana foram garantidos no texto final da Constituição de 1988. Quais interesses estiveram em disputa? Qual o debate na Subcomissão? Quais eram as posições dos setores e instituições que foram incluídos no debate?

\section{A Subcomissão da Questão Urbana e Transportes na Constituinte (1987)}

A Assembleia Nacional Constituinte foi instalada em primeiro de fevereiro de 1987, e representou a realização da transição democrática iniciada em 1985. Os deputados federais e senadores eleitos pelo voto direto tiveram a incumbência de redigir a nova carta constitucional que sepultaria definitivamente o regime autoritário brasileiro, como acreditava-se naquela época. A Subcomissão da Questão Urbana e Transporte foi uma das três subcomissões da Comissão da Ordem Econômica. Ao todo foram criadas oito comissões temáticas, cada uma delas com três subcomissões, cujos temas e regras de funcionamento foram definidos por regimento em 20 de março de 1987 (Brasil, 1987a). As subcomissões tinham ao todo 45 dias contados da sua criação para encaminhar à comissão temática o "Anteprojeto da Subcomissão". Esse prazo de 
tramitação do Anteprojeto na Subcomissão incluía audiências públicas, debates, emendas, pareceres e votação. 0 Anteprojeto da Subcomissão ainda seria submetido a novas revisões nas três fases seguintes, no âmbito da comissão temática, depois no âmbito da comissão sistematizadora e finalmente no plenário da Assembleia Nacional Constituinte. No âmbito das subcomissões, o regimento interno determinava que houvesse de cinco a oito reuniões em forma de audiências públicas. 0 regimento também determinava que os anteprojetos iniciais deveriam ser propostos pelos relatores em 30 dias, sobrando quinze dias para debates, emendas, pareceres, votações e redação final do "Anteprojeto da Subcomissão".

A Subcomissão da Questão Urbana e Transportes foi instalada em 7 de abril de 1987 e foram realizados ao todo 22 encontros até 23 de maio de 1987, quando ocorreu a votação do "Anteprojeto da Subcomissão". Destas reuniões, 12 foram audiências públicas quando foram ouvidos vários setores da sociedade ligados à questão urbana (Tabela 1). Nesses encontros, os expositores se debruçaram sobre diversos temas específicos relativos à questão urbana, tais como: a política urbana, os sistemas de transportes em suas várias modalidades, o transporte coletivo, a política habitacional, o desenvolvimento urbano e a gestão democrática das cidades. Entre esses temas, a política habitacional e urbana e o transporte público foram os mais recorrentes nos debates.

Tabela 1 - Cronograma dos 22 encontros da Subcomissão da Questão Urbana e Transportes

\begin{tabular}{|c|c|c|c|c|}
\hline $\begin{array}{l}\text { REUNIÃO } \\
\text { ORDINÁRIA } \\
\text { (R)/AUDIÊNCIA } \\
\text { PÚBLICA (A) }\end{array}$ & $\begin{array}{l}\text { DATA } \\
\text { (hora) }\end{array}$ & PAUTA & INSTITUIÇÕES REPRESENTADAS & SETORES SOCIAIS \\
\hline $\begin{array}{l}01 \\
\text { REUNIÃO DE } \\
\text { INSTALAÇÃO }\end{array}$ & $\begin{array}{l}7 / 4 \\
(15 h 15)\end{array}$ & $\begin{array}{l}\text { Administrativa/ } \\
\text { Instalação da subcomissão }\end{array}$ & & \\
\hline $\begin{array}{l}02 \\
\text { R01 }\end{array}$ & $\begin{array}{l}13 / 4 \\
(12 h 00)\end{array}$ & Administrativa & Não houve & \\
\hline \multirow[t]{2}{*}{$\begin{array}{l}03 \\
\text { R02/A01 }\end{array}$} & $\begin{array}{l}13 / 4 \\
(18 h 50)\end{array}$ & $\begin{array}{l}\text { Audiência Pública/ } \\
\text { Política urbana/ } \\
\text { Habitação/ Transportes }\end{array}$ & $\begin{array}{l}\text { Instituto dos Arquitetos do Brasil } \\
\text { Federação Nacional dos Arquitetos } \\
\text { Associação Brasileira de Ensino de } \\
\text { Arquitetura (Asbea) }\end{array}$ & $\begin{array}{l}\text { PROFISSIONAL LIBERAL } \\
\text { (ARQUITETOS) }\end{array}$ \\
\hline & & & $\begin{array}{l}\text { Empresa Brasileira de Transporte } \\
\text { Urbano }\end{array}$ & ESTADO/ ESTATAL \\
\hline $\begin{array}{l}04 \\
\text { R03 }\end{array}$ & $\begin{array}{l}22 / 4 \\
(10 h 20)\end{array}$ & Administrativa & Não houve & \\
\hline $\begin{array}{l}05 \\
\text { R04 }\end{array}$ & $\begin{array}{l}\mathbf{2 2 / 4} \\
(18 \mathrm{~h} 08)\end{array}$ & Administrativa & Não houve & \\
\hline $\begin{array}{l}06 \\
\text { R05/A02 }\end{array}$ & $\begin{array}{l}\mathbf{2 3 / 4} \\
(10 h 28)\end{array}$ & $\begin{array}{l}\text { Audiência Pública/ Política } \\
\text { urbana/ Transportes }\end{array}$ & $\begin{array}{l}\text { Arquiteto } \\
\text { Sociólogo } \\
\text { Arquiteto e Urbanista } \\
\text { Especialista em Transportes }\end{array}$ & $\begin{array}{l}\text { ESTADO/ ASSESSORES } \\
\text { PARLAMENTARES }\end{array}$ \\
\hline $\begin{array}{l}07 \\
\text { R06/A03 }\end{array}$ & $\begin{array}{l}23 / 4 \\
(17 h 43)\end{array}$ & $\begin{array}{l}\text { Audiência Pública/ } \\
\text { Transporte coletivo }\end{array}$ & $\begin{array}{l}\text { Prefeito de Curitiba /Associação } \\
\text { Brasileira de Prefeitos de Capitais } \\
\text { Prefeito de Juazeiro/ Presidente da } \\
\text { Confederação Brasileira dos } \\
\text { Municípios } \\
\text { Associação dos Municípios da Grande } \\
\text { São Paulo }\end{array}$ & ESTADO/MUNICÍPIOS \\
\hline $\begin{array}{l}08 \\
\text { R07/A04 }\end{array}$ & $\begin{array}{l}\mathbf{2 4 / 4} \\
(17 h 55)\end{array}$ & $\begin{array}{l}\text { Audiência Pública/ } \\
\text { Transporte coletivo }\end{array}$ & $\begin{array}{l}\text { Arquiteto } \\
\text { Especialista em Transportes }\end{array}$ & $\begin{array}{l}\text { ESTADO/ ASSESSORES } \\
\text { PARLAMENTARES }\end{array}$ \\
\hline
\end{tabular}


Tabela 1 - Cronograma dos 22 encontros da Subcomissão da Questão Urbana e Transportes

(continuação)

\begin{tabular}{|c|c|c|c|c|}
\hline $\begin{array}{l}\text { REUNIÃO } \\
\text { ORDINÁRIA } \\
\text { (R)/AUDIÊNCIA } \\
\text { PÚBLICA (A) }\end{array}$ & $\begin{array}{l}\text { DATA } \\
\text { (hora) }\end{array}$ & PAUTA & INSTITUIÇŌES REPRESENTADAS & SETORES SOCIAIS \\
\hline \multirow[t]{7}{*}{$\begin{array}{l}09 \\
\text { R08/A05 }\end{array}$} & \multirow[t]{7}{*}{$\begin{array}{l}28 / 4 \\
(10 h 55)\end{array}$} & \multirow[t]{7}{*}{$\begin{array}{l}\text { Audiência Pública/ } \\
\text { Transporte marítimo }\end{array}$} & $\begin{array}{l}\text { Superintendência Nacional da Marinha } \\
\text { Mercante }\end{array}$ & \multirow{7}{*}{$\begin{array}{l}\text { ESTADO/ VÁRIOS } \\
\text { SETORES } \\
\text { LIGADOS AO } \\
\text { TRANSPORTE } \\
\text { MARIIIMO }\end{array}$} \\
\hline & & & Federação Nacional dos Marítimos & \\
\hline & & & $\begin{array}{l}\text { Associação Brasileira dos Armadores de } \\
\text { Cabotagem }\end{array}$ & \\
\hline & & & $\begin{array}{l}\text { Associação dos Armadores Brasileiros de Longo } \\
\text { Curso }\end{array}$ & \\
\hline & & & $\begin{array}{l}\text { Associação Nacional dos Armadores de Roll-on } \\
\text { e Roll-off e Transporte Intermodal }\end{array}$ & \\
\hline & & & Departamento de Vias Navegáveis da Portobras & \\
\hline & & & Companhia de Navegação Lloyd Brasileiro & \\
\hline \multirow[t]{3}{*}{$\begin{array}{l}10 \\
\text { R09/A06 }\end{array}$} & \multirow[t]{3}{*}{$\begin{array}{l}28 / 4 \\
(18 \mathrm{~h} 35)\end{array}$} & \multirow[t]{3}{*}{$\begin{array}{l}\text { Audiência Pública/ } \\
\text { Política urbana }\end{array}$} & $\begin{array}{l}\text { Ministro do Desenvolvimento Urbano e Meio } \\
\text { Ambiente }\end{array}$ & $\overline{\text { ESTADO }}$ \\
\hline & & & Prefeito de Porto Velho & ESTADO/ \\
\hline & & & Prefeito de Divinópolis & MUNICÍPIO \\
\hline \multirow{3}{*}{$\begin{array}{l}11 \\
\text { R10/A07 }\end{array}$} & \multirow{3}{*}{$\begin{array}{l}29 / 4 \\
(10 h 09)\end{array}$} & \multirow{3}{*}{$\begin{array}{l}\text { Audiência Pública/ } \\
\text { Transporte aéreo / } \\
\text { ferroviário }\end{array}$} & Departamento de Aviação Civil (DAC) & \multirow{2}{*}{$\begin{array}{l}\text { ESTADO/ } \\
\text { ESTATAL }\end{array}$} \\
\hline & & & $\begin{array}{l}\text { Companhia Brasileira de Transporte Urbano } \\
\text { (CBTU) }\end{array}$ & \\
\hline & & & $\begin{array}{l}\text { Confederação Nacional dos Transportes } \\
\text { Marítimos, Fluviais e Aéreos }\end{array}$ & $\begin{array}{l}\text { SINDICAL } \\
\text { PATRONAL }\end{array}$ \\
\hline \multirow[t]{8}{*}{$\begin{array}{l}12 \\
\text { R11/A08 }\end{array}$} & \multirow[t]{8}{*}{$\begin{array}{l}30 / 4 \\
(10 h 10)\end{array}$} & \multirow{8}{*}{$\begin{array}{l}\text { Audiência Pública/ } \\
\text { Transporte coletivo/ } \\
\text { terrestre /rodoviário }\end{array}$} & $\begin{array}{l}\text { Departamento Nacional de Estradas de } \\
\text { Rodagem (DNER) }\end{array}$ & ESTATAL \\
\hline & & & $\begin{array}{l}\text { Associação Nacional de Transportes Públicos } \\
\text { Sindicato dos Engenheiros de São Paulo }\end{array}$ & $\begin{array}{l}\text { PROFISSIONAL } \\
\text { LIBERAL } \\
\text { (ENGENHEIROS) }\end{array}$ \\
\hline & & & $\begin{array}{l}\text { Confederação Nacional dos Transportes } \\
\text { Terrestres }\end{array}$ & \multirow[t]{4}{*}{$\begin{array}{l}\text { SINDICATO } \\
\text { PATRONAL }\end{array}$} \\
\hline & & & $\begin{array}{l}\text { Federação Norte-Nordeste das Empresas de } \\
\text { Transportes Rodoviários de Carga }\end{array}$ & \\
\hline & & & $\begin{array}{l}\text { Associação Nacional das Empresas de } \\
\text { Transportes Interestaduais e Internacionais de } \\
\text { Passageiros }\end{array}$ & \\
\hline & & & $\begin{array}{l}\text { Sindicato dos Indústrias de Transporte do Distrito } \\
\text { Federal }\end{array}$ & \\
\hline & & & $\begin{array}{l}\text { Confederação Nacional dos Trabalhadores em } \\
\text { Transportes Terrestres }\end{array}$ & \multirow[t]{2}{*}{$\begin{array}{l}\text { SINDICATO } \\
\text { TRABALHADORES }\end{array}$} \\
\hline & & & $\begin{array}{l}\text { Sindicato dos Transportadores Autônomos } \\
\text { Rodoviários de Bens do ABC }\end{array}$ & \\
\hline $\begin{array}{l}\text { 13 } \\
\text { R12/A09 }\end{array}$ & $\begin{array}{l}4 / 5 \\
(17 h 30)\end{array}$ & $\begin{array}{l}\text { Audiência Pública/ } \\
\text { Política urbana / } \\
\text { Habitação / } \\
\text { Transporte coletivo }\end{array}$ & $\begin{array}{l}\text { Caixa Econômica Federal } \\
\text { Conselho Nacional do Desenvolvimento Urbano } \\
\text { Empresa Brasileira de Transportes Urbanos }\end{array}$ & $\begin{array}{l}\text { ESTADO/ } \\
\text { ESTATAL }\end{array}$ \\
\hline \multirow{2}{*}{$\begin{array}{l}14 \\
\text { R13/A10 }\end{array}$} & \multirow{2}{*}{$\begin{array}{l}\mathbf{5 / 5} \\
(9 \mathrm{~h} 54)\end{array}$} & \multirow{2}{*}{$\begin{array}{l}\text { Audiência Pública/ } \\
\text { Política urbana / } \\
\text { Habitação }\end{array}$} & Câmara Brasileira da Indústria da Construção & \multirow{2}{*}{$\begin{array}{l}\text { SINDICATO } \\
\text { PATRONAL }\end{array}$} \\
\hline & & & $\begin{array}{l}\text { Sindicato Nacional da Indústria de Construção } \\
\text { de Estradas, Pontes, Portos, Aeroportos, } \\
\text { Barragens e Pavimentação } \\
\text { Sindicato das Empresas de Compra e Venda, } \\
\text { Locação e Administração de Imóveis de São } \\
\text { Paulo }\end{array}$ & \\
\hline 15 & $5 / 5$ & Administrativa/ & Não houve & \\
\hline R14 & $(18 h 00)$ & Leitura de sugestões & & \\
\hline
\end{tabular}


Tabela 1 - Cronograma dos 22 encontros da Subcomissão da Questão Urbana e Transportes

\begin{tabular}{|c|c|c|c|c|}
\hline $\begin{array}{l}\text { REUNIÃO } \\
\text { ORDINÁRIA } \\
\text { (R)/AUDIÊNCIA } \\
\text { PÚBLICA (A) }\end{array}$ & $\begin{array}{l}\text { DATA } \\
\text { (hora) }\end{array}$ & PAUTA & INSTITUIÇÕES REPRESENTADAS & SETORES SOCIAIS \\
\hline \multirow[t]{4}{*}{$\begin{array}{l}16 \\
\text { R15/A11 }\end{array}$} & \multirow[t]{4}{*}{$\begin{array}{l}6 / 5 \\
(10 h 16)\end{array}$} & \multirow{4}{*}{$\begin{array}{l}\text { Audiência Pública/ } \\
\text { Política urbana / } \\
\text { Habitação/ Transporte } \\
\text { coletivo }\end{array}$} & $\begin{array}{l}\text { Sociedade Brasileira Para o } \\
\text { Progresso da Ciência (SBPC) }\end{array}$ & CIENTISTAS \\
\hline & & & $\begin{array}{l}\text { Sindicato dos Arquitetos do } \\
\text { Estado de São Paulo (MNRU) } \\
\text { Sindicato dos Engenheiros do Rio } \\
\text { de Janeiro (MNRU) }\end{array}$ & PROFISSIONAIS LIBERAIS/ MNRU \\
\hline & & & $\begin{array}{l}\text { Associação dos Trabalhadores da } \\
\text { Zona Norte de São Paulo (MNRU) } \\
\text { Articulação Nacional do Solo } \\
\text { Urbano (MNRU) } \\
\text { Associação dos Mutuários do } \\
\text { Ceará (MNRU) } \\
\text { Federação Rio-grandense de } \\
\text { Associações Comunitárias e } \\
\text { Amigos de Bairro (MNRU) } \\
\text { Federação de Mutuários de São } \\
\text { Paulo (MNRU) } \\
\text { Movimento Unificado de Favelas, } \\
\text { Cortiços e Promorar (MNRU) } \\
\text { Centro do Trabalhador para } \\
\text { Defesa da Terra 'Paulo Canarim' } \\
\text { (MNRU) } \\
\text { Associação dos Usuários dos } \\
\text { Transportes Coletivos do Estado } \\
\text { de São Paulo (MNRU) } \\
\text { Movimento dos Sem-Terra (MNRU) } \\
\text { Federação das Associações de } \\
\text { Moradores do Rio de Janeiro } \\
\text { (MNRU) } \\
\text { Associação dos Inquilinos da } \\
\text { Ceilândia (MNRU) }\end{array}$ & $\begin{array}{l}\text { MOVIMENTOS SOCIAIS URBANOS / } \\
\text { MNRU }\end{array}$ \\
\hline & & & $\begin{array}{l}\text { Confederação Nacional das } \\
\text { Associações de Moradores } \\
\text { (CONAM) } \\
\text { Federação das Associações de } \\
\text { Moradores do Estado do Piauí } \\
\text { (FAMEPI) }\end{array}$ & MOVIMENTOS SOCIAIS URBANOS \\
\hline $\begin{array}{l}17 \\
\text { R16 }\end{array}$ & $\begin{array}{l}12 / 5 \\
(18 h 00)\end{array}$ & Anteprojeto & Não houve & \\
\hline $\begin{array}{l}18 \\
\text { R17 }\end{array}$ & $\begin{array}{l}13 / 5 \\
(18 \mathrm{~h} 23)\end{array}$ & Anteprojeto & Não houve & \\
\hline $\begin{array}{l}19 \\
\text { R18 }\end{array}$ & $\begin{array}{l}\mathbf{1 4 / 5} \\
(11 \mathrm{~h} 03)\end{array}$ & Anteprojeto & Não houve & \\
\hline $\begin{array}{l}20 \\
\text { R19/A12 }\end{array}$ & $\begin{array}{l}14 / 5 \\
(18 h 20)\end{array}$ & $\begin{array}{l}\text { Audiência Pública/ } \\
\text { Emendas ao anteprojeto: } \\
\text { transportes aéreos }\end{array}$ & $\begin{array}{l}\text { Sindicato Nacional dos } \\
\text { Aeronautas }\end{array}$ & SINDICATO TRABALHADORES \\
\hline $\begin{array}{l}21 \\
R 20\end{array}$ & $\begin{array}{l}19 / 5 \\
(18 \mathrm{~h} 19)\end{array}$ & Anteprojeto & Não houve & \\
\hline $\begin{array}{l}22 \\
\text { REUNIĀO } \\
\text { EXTRAORDINÁRIA }\end{array}$ & $\begin{array}{l}\mathbf{2 3 / 5} \\
(21 \mathrm{~h} 05)\end{array}$ & $\begin{array}{l}\text { Anteprojeto / Votação } \\
\text { do Anteprojeto da } \\
\text { Subcomissão }\end{array}$ & Não houve & \\
\hline
\end{tabular}

Nota: Elaborada pelos autores com base no Cronograma dos vinte e dois encontros da Subcomissão da Questão Urbana e dos transportes ocorridos entre 7/04 e 23/05 de 1987. Na tabela encontram-se indicadas as vinte reuniões ordinárias e as doze audiências públicas identificadas com data, horário, pauta da reunião, instituições representadas e setores sociais a que pertencem. Observa-se a predominância de setores ligados ao Estado, presente em nove audiências, seguidos dos profissionais liberais e sindicatos patronais, presentes em três audiências públicas, sindicatos dos trabalhadores, presente em duas audiências públicas e movimentos sociais presentes em uma audiência pública. Complementada pelos autores. Fonte: Câmara dos Deputados (1987). 


\section{A política urbana em debate na Subcomissão}

Logo na segunda reunião ordinária (primeira audiência pública da Subcomissão) foram convidados expositores externos para debater principalmente a política habitacional e urbana. Os expositores foram representando o Instituto de Arquitetos do Brasil (IAB), a Federação Nacional de Arquitetos (FNA), a Associação Brasileira de Escolas de Arquitetura (ABEA) e a Empresa Brasileira de Transporte Urbano (EBTU). Nessa reunião já estavam anunciados os dois pontos importantes debatidos nas reuniões seguintes da Subcomissão: se o Estado deveria financiar um programa de habitação popular, e quais deveriam ser os instrumentos para regular "a função social da propriedade urbana". Temas introduzidos pelos Congressistas através da avaliação da experiência recente do Banco Nacional de Habitação (BNH) que havia sido extinto em 1986, e do projeto proposto pela Comissão Nacional de Desenvolvimento Urbano (CNDU), o Projeto de Lei 775 de 1983 (Brasil, 1987c, p. 29-42).

Foi nessa reunião também que as instituições dos arquitetos (IAB, FNA, ABEA) apresentaram uma proposta sintética que afirmava o direito à moradia digna, a prioridade do uso social das terras urbanas sobre o direito de propriedade e a gestão democrática, participativa e transparente da cidade. Quanto aos instrumentos urbanísticos da reforma urbana, a proposta incluiu a desapropriação dos terrenos mediante títulos da dívida pública e o IPTU progressivo. Ambas as medidas facilitariam a formação de um estoque de terra urbana pelo poder público, incluído na proposta. Também reconheceu o direito à usucapião depois de três anos de ocupação do imóvel, o direito de preempção e limitou os lucros imobiliários através de um imposto específico (Brasil, 1987c, p. 30).

As audiências públicas seguintes iniciaram-se na quinta reunião ordinária da Subcomissão e foram convidados vários expositores ligados ao tema dos transportes em suas várias modalidades. Embora a política urbana e habitacional continuasse a ser debatida tanto pelos expositores quanto pelos congressistas e seus assessores, como ocorreu na sexta e nona reuniões da Subcomissão, foi apenas nas três audiências públicas realizadas entre a décima segunda e a décima quinta reunião ordinária da Subcomissão que os expositores apresentaram novas propostas para a política urbana brasileira.

Na décima segunda reunião vieram representantes de três empresas estatais: a Caixa Econômica Federal (CEF), o Conselho Nacional do Desenvolvimento Urbano (CNDU) e a Empresa Brasileira de Transportes Urbanos (EBTU). Coube ao arquiteto Gervásio Cardoso de Oliveira Filho, Secretário da CNDU, apresentar uma nova proposta de reforma urbana provinda da mesma instituição que havia proposto o PL 775/83. A proposta apresentada à Subcomissão defendia os mesmos princípios do projeto de lei anterior. Os princípios básicos eram a inclusão do direito à moradia nas garantias individuais, a restrição do direito de propriedade à função social da propriedade e a desvinculação do direito de propriedade e do direito de construir. Segundo a proposta apresentada, a utilização do solo urbano deveria obedecer às exigências fundamentais da ordenação urbana e ambiental expressas em planos urbanísticos elaborados pelo poder público. A lei deveria definir as condições nas quais o proprietário seria compelido, em prazo determinado, a sua utilização socialmente adequada, sob pena de desapropriação por interesse social ou de incidência de medidas de caráter tributário, incluindo o imposto progressivo e a desapropriação por títulos da dívida pública. Portanto, origina-se dessa proposta os princípios básicos presentes na Constituição Federal de 1988, isto é, os planos diretores obrigatórios que determinam a função social da propriedade e a aplicação das medidas restritivas ao direito de propriedade, como o Parcelamento e Edificação Compulsórios, O IPTU progressivo e a desapropriação mediante títulos da dívida pública. Oliveira defendeu a função social da propriedade submetida ao ordenamento dos planos urbanísticos, evidenciando a disputa entre os interesses dos setores ligados à Construção Civil e ao mercado imobiliário e da burocracia técnica do Conselho Nacional de Desenvolvimento Urbano.

Marcos Freire, então presidente da Caixa Econômica Federal, defendeu mecanismos para limitar o direito de propriedade e facilitar a exploração do solo. Sua posição privilegia o desenvolvimento econômico urbano em relação ao direito de propriedade. A função permitia, sobretudo, liberar potencial construtivo para a indústria da construção civil e para a produção de moradia dentro de um novo programa habitacional. 
$\mathrm{Na}$ reunião seguinte, foi a vez do setor privado apresentar sua proposta. Nessa reunião foram convidados os representantes da Câmara Brasileira da Indústria da Construção e do Sindicato das Empresas de Compra e Venda, Locação e Administração de Imóveis de São Paulo. Coube a Carlos Moacyr Gomes de Almeida, membro do Conselho Diretor da Câmara Brasileira da Indústria da Construção apresentar a proposta do setor privado. Sua fala recupera o histórico das políticas de desenvolvimento urbano desde o início do período militar e critica explicitamente o projeto de lei do desenvolvimento urbano PL 775/83, considerando-o "incompleto e inconveniente" e ainda uma "ameaça ao regime de propriedade e à operação privada de nossa economia" (Brasil, 1987h, p. 51-54). Almeida apresenta uma proposta de substitutivo ao projeto de lei de 1983, que havia sido produzida no âmbito do Grupo de Trabalho para Reformulação do Sistema Financeiro da Habitação, criado pelo então Presidente José Sarney. Essa proposta tinha como objetivo reformular o BNH apresentando uma nova política habitacional, inserida em uma política mais ampla de desenvolvimento urbano, atendendo aos interesses da indústria da construção. Foi apresentada na Subcomissão com o título Uma proposta para orientar a elaboração de um Plano Nacional de Desenvolvimento urbano e sua implementação. A proposta define a exclusividade da iniciativa privada para lotear glebas, construir ou incorporar edificações. As empresas públicas seriam admitidas em casos de projetos especais de interesse social (tipo COHAB) ou de desenvolvimento econômico (tipo distritos industriais).

$\mathrm{Na}$ audiência pública seguinte, décima quinta reunião ordinária, foram ouvidos e apresentaram propostas os representantes da Sociedade Brasileira para o Progresso da Ciência (SBPC), do Movimento Nacional pela Reforma Urbana (MNRU), da Confederação Nacional das Associações de Moradores (CONAM) e da Federação Nacional de Moradores do Piauí (FAMEPI). A SBPC, representada pelo geógrafo Milton Santos (1926-2001), foi a primeira convidada a se pronunciar. Em sua fala marcante, Santos explicou que as relações do homem com o território constituem uma forma cultural e política inseparável do conceito de cidadania. Portanto, a ampliação democrática da cidadania brasileira deveria considerar que o território fosse uma instância de produção de igualdade e não o seu inverso. Defendeu, assim, a produção de um novo pacto político-territorial, sob a recém instituída democracia, ressaltando que a reforma urbana era uma parte desse novo pacto social (Brasil, 1987i, p. 88-90).

Em seguida, Nabil Bonduki e os demais representantes do MNRU apresentaram a proposta que seria mais tarde encaminhada à Comissão Sistematizadora, e que ficou conhecida como Emenda Popular n. 63, que dispõem sobre a reforma urbana. Bonduki apresenta as 63 entidades de várias localidades que se reuniram para formar o movimento. Eram entidades ligadas aos movimentos sociais urbanos, à defesa dos direitos humanos, à igreja, sindicatos e associações de classe. Bonduki apresenta a proposta do MNRU por meio de quatro pontos básicos: 1) garantir os direitos urbanos; 2) limitar o direito de propriedade e controlar o direito de construir; 3) garantir que a produção da cidade, moradia, transportes e serviços públicos sejam uma responsabilidade do Estado e 4) garantir a participação da comunidade no processo de desenvolvimento urbano. Em sua apresentação da proposta, ele defende que a questão urbana ocupe um capítulo específico na Constituição. Outros integrantes da articulação como Franklin Coelho, do Sindicato dos Engenheiros do Rio de Janeiro, e Flora Eujace Maranhão, da Articulação Nacional do Solo Urbano, detalharam a proposta do movimento apresentando os instrumentos urbanísticos da reforma urbana presentes nas propostas anteriores como o Parcelamento e edificação compulsórios, a desapropriação mediante pagamento através de títulos da dívida pública, o IPTU progressivo e o direito de preempção (Brasil, 1987i, p. 90-99).

A CONAM apresentou uma pauta extensa, com 24 pontos que incluíam o direito à moradia pelos trabalhadores assalariados, que o custo de moradia não ultrapassasse $20 \%$ do salário do trabalhador, dimensões mínimas das unidades, criação de um Fundo Municipal de Habitação, com o objetivo de garantir $15 \%$ do orçamento da União para o investimento em moradia, investir em pesquisa e qualidade para reduzir os custos da unidade e melhorar o produto oferecido pelos programas habitacionais, adotar mecanismos restritivos do direito de propriedade como o IPTU progressivo e a desapropriação, urbanização de favelas, 
gestão participativa e ainda uma política de transporte público com subsídios e isenções (Brasil, 1987i, p. 102-103).

A FAMEPI defendeu uma proposta com onze pontos que incluíam o direito universal à moradia digna, a gestão participativa, o adensamento nas áreas urbanas já dotadas de infraestruturas, moradias próximas ao centro, desapropriação de terrenos ociosos, redução da prestação da casa própria ao preço de custo, dotação orçamentária de 15\% para o investimento em habitação, IPTU progressivo, transporte público subsidiado, gestão participativa nas políticas urbanas e de transportes (Brasil, 1987i, p. 104-105).

Na reunião seguinte (16 $\left.{ }^{a}\right)$ o Relator da Subcomissão, o Constituinte José Ulisses de Oliveira (PMDB), apresentou o "Anteprojeto do Relator". A apresentação do Anteprojeto foi antecedida por um balanço que legitimava o processo participativo democrático na elaboração do documento. Foram 46 entidades recebidas pela Subcomissão em audiências públicas, sendo que 54 entidades e 159 Constituintes registraram suas sugestões. 0 "Anteprojeto do Relator" foi então debatido nas reuniões seguintes (17aㅗ $18^{\text {a }}$ e 19â), quando os integrantes da Subcomissão apresentaram diversas contribuições e emendas ao "Anteprojeto do Relator". Na última reunião ordinária coube ainda ao Relator apresentar o "Anteprojeto da Subcomissão".

O "Anteprojeto da Subcomissão" incluiu muitos temas debatidos durante as audiências públicas que trataram da política urbana, como por exemplo o direito à moradia digna, a manutenção do Sistema Financeiro da Habitação, a criação de um Conselho Metropolitano. Incluiu também outros temas presentes no debate da sociedade civil organizada, como por exemplo a preservação da memória urbana, o direito das populações locais (bairros) proporem projetos de lei representando seus interesses específicos, a proteção ao meio ambiente e o controle da poluição.

Apesar disso, o texto causou polêmica entre os integrantes da Subcomissão, pois sequer incluía os instrumentos urbanísticos de restrição do direito de propriedade do solo urbano, reiteradamente apontados pelos setores técnicos e também reivindicados pelos representantes dos movimentos sociais urbanos. O IPTU progressivo e o Parcelamento Compulsório seriam incluídos posteriormente na Constituição de 1988 através de emenda popular.

0 texto do "Anteprojeto da Subcomissão" foi votado na vigésima primeira reunião, encerrando assim o ciclo de debates sobre a questão urbana no âmbito da Subcomissão. 0 texto aprovado permitia as inversões do Estado no setor habitacional e apontava para uma política pública de habitação, entretanto o direito de propriedade continuava garantido através das desapropriações exclusivamente em dinheiro.

As posições discutidas acima constituem os principais pontos de debate dos setores sociais ouvidos durante as reuniões da Subcomissão, conforme apresentado na Tabela 2. A sistematização das propostas, que levaram ao capítulo sobre a política urbana na Constituição Brasileira de 1988, permite compreender o complexo de agentes e visões sobre a questão urbana ativas na sociedade brasileira no final da década de oitenta, embora muitas delas não tenham sido incorporadas no texto constitucional, permaneceram ativas, influenciando na tomada de decisões sobre as políticas públicas nas décadas seguintes. 
Tabela 2 - Síntese das posições defendidas no debate sobre a política urbana durantes as reuniões da Subcomissão da Questão Urbana e Transportes por instituições e setores sociais

(continua)

\begin{tabular}{l}
\hline INSTITUIÇÕES \\
REPRESENTADAS \\
\hline PROFISSIONAIS LIBERAIS \\
\hline Instituto dos Arquitetos do \\
Brasil (Fábio Goldman)
\end{tabular}

\section{Associação Brasileira de Ensino de Arquitetura (Miguel Pereira)}

Federação Nacional dos Arquitetos (Orlando Cariello)

\section{EMPRESAS ESTATAIS}

Caixa Econômica Federal (Marcos Freire)

\section{Empresa Brasileira de Transportes Urbanos (Antonio Rebelo)}

\section{Conselho Nacional do Desenvolvimento Urbano (Gervásio Cardoso)}

\section{POSIÇÃO DEFENDIDA}

A qualidade de vida é intimamente ligada à questão do desenvolvimento urbano da cidade. $O$ acesso às informações sobre a gestão urbana e a participação nas decisões (gestão democrática da cidade). A proposta apresentada em conjunto com a ABEA e FNA firmava o direito à moradia digna, a prioridade do uso social das terras urbanas sobre o direito de propriedade e a gestão democrática, participativa e transparente da cidade. Quanto aos instrumentos urbanísticos da reforma urbana, a proposta incluiu a desapropriação dos terrenos mediante títulos da dívida pública e o IPTU progressivo. Ambas as medidas facilitariam a formação de um estoque de terra urbana pelo poder público, incluído na proposta. Também reconheceu o direito à usucapião depois de três anos de ocupação do imóvel, o direito de preempção e limitou os lucros imobiliários através de um imposto específico.

Defende uma política para o ensino de arquitetura no contexto da expansão do setor privado.

Defende priorizar a finalidade social da propriedade. Correlação entre a questão sindical e a questão urbana. Estabelecer uma política habitacional do desenvolvimento urbano vinculado ao desenvolvimento das condições de vida da população trabalhadora.

Defende que o "processo de urbanismo galopante" tenha um regramento federal e não fique na dependência do "disciplinamento" do município. Defende uma política habitacional que considere todas as variáveis que interferem no problema da moradia. "Para exemplificar, conjuntos habitacionais construídos sem a necessária previsão do saneamento, ou do arruamento, ou do esgoto sanitário, ou do abastecimento d'água, tudo isto deformando, tudo isto agravando o problema habitacional que deveria ser resolvido através de uma solução conseqüentemente plena e integral." Defende a desapropriação de terrenos urbanos para uso em políticas sociais de habitação.

Apresenta o transporte como um setor chave da economia, relacionado com a soberania nacional. Destaca dois pontos essenciais: a tarifa de transportes e o desenvolvimento tecnológico. Defende uma política de subsídio para o setor.

Defendem a "formulação de novos instrumentos jurídicos que permitam maior controle do Poder Público sobre a propriedade privada". Sugerem 3 artigos para a constituição: a utilização do solo urbano segundo a ordenação urbana e ambiental expressas nos planos urbanísticos; o munícipio e as aglomerações urbanas são responsáveis pela elaboração dos planos urbanísticos; a desapropriação para fins do desenvolvimento urbano. Sugerem a desvinculação do direito de propriedade do direito de construir. Sobre a habitação defendem a inclusão do direito à moradia nas garantias individuais e afirmam que "deverá ser tratada dentro do contexto do desenvolvimento urbano, em conjunto com os demais aspectos urbanos, saneamento, transporte, sistema viário, uso do solo, propriedade imobiliária e urbana, saúde, educação, recreação e lazer e outros, como um conjunto de medidas articuladas entre si."

MERCADO IMOBILIÁRIO

Sindicato das Empresas de Compra e Venda, Locação e Administração de Imóveis de São Paulo (Paulo A. G. Germano) Câmara Brasileira da Indústria da Construção (Carlos Moacyr Gomes de Almeida)

Apresenta uma proposta de estímulo da locação, através da garantia da propriedade, da eliminação da interferência do Estado nas relações entre as partes, no mercado de locação, "procurar mecanismos de estímulo, sobretudo, ao investimento de todo o produto de locação, que fosse reinvestido na oferta de novos imóveis para locação, ele deveria ser isentado de Imposto de Renda."

Apresentaram o documento "Uma proposta para orientar a elaboração de um Plano Nacional de Desenvolvimento urbano e sua implementação". Nesse plano definem o papel da iniciativa privada, a quem caberia a exclusividade para lotear glebas, construir ou incorporar edificações, admitindo-se, em caráter excepcional, a ação empresarial de empresas públicas em projetos de especial interesse social (tipo $\mathrm{COHAB}$ ) ou de desenvolvimento econômico (tipo distritos industriais), "onde a iniciativa privada, subsidiada de forma equivalente, não quiser assumir os riscos neles implícitos". 
Tabela 2 - Síntese das posições defendidas no debate sobre a política urbana durantes as reuniões da Subcomissão da Questão Urbana e Transportes por instituições e setores sociais

(conclusão)

\begin{tabular}{|c|c|}
\hline INSTITUIÇÕES REPRESENTADAS & POSIÇÃO DEFENDIDA \\
\hline \multicolumn{2}{|l|}{ INTELECTUAIS } \\
\hline $\begin{array}{l}\text { Sociedade Brasileira Para o } \\
\text { Progresso da Ciência - SBPC } \\
\text { (Milton Santos) }\end{array}$ & $\begin{array}{l}\text { Defesa de um 'Pacto Territorial' como reflexo de um } \\
\text { encontra precedentes em outros pontos importante } \\
\text { Avalia momentos como a Era Vargas, a Construção } \\
\text { formações de novos pactos territoriais e sociais, e vê } \\
\text { novo pacto social em curso a possibilidade de fund } \\
\text { para o Brasil. }\end{array}$ \\
\hline \multicolumn{2}{|c|}{ MOVIMENTOS SOCIAIS URBANOS } \\
\hline $\begin{array}{l}\text { Sindicato dos Arquitetos do } \\
\text { Estado de São Paulo (MNRU) } \\
\text { Sindicato dos Engenheiros } \\
\text { do Rio de Janeiro (MNRU) } \\
\text { Associação dos } \\
\text { Trabalhadores da Zona Norte } \\
\text { de São Paulo (MNRU) } \\
\text { Articulação Nacional do } \\
\text { Solo Urbano (MNRU) } \\
\text { Associação dos Mutuários } \\
\text { do Ceará (MNRU) } \\
\text { Federação Rio-grandense } \\
\text { de Associações } \\
\text { Comunitárias e Amigos de } \\
\text { Bairro (MNRU) } \\
\text { Federação de Mutuários de Sa }\end{array}$ & $\begin{array}{l}\text { A proposta do MNRU organizava-se em quatro pont } \\
\text { direitos urbanos; 2) limitar o direito de propriedade e } \\
\text { construir; 3) garantir que a produção da cidade, mo } \\
\text { serviços públicos sejam uma responsabilidade do Est } \\
\text { participação da comunidade no processo de deser } \\
\text { apresentação da proposta, ele defende que a ques } \\
\text { capítulo específico na Constituição. Outros integran } \\
\text { Franklin Coelho do Sindicato dos Engenheiros do Rio } \\
\text { Maranhão da Articulação Nacional do Solo Urbano } \\
\text { movimento apresentando os instrumentos urbanístic } \\
\text { presentes nas propostas anteriores como o Parcelar } \\
\text { compulsórios, a desapropriação mediante pagame } \\
\text { dívida pública, o IPTU progressivo e o direito de pree }\end{array}$ \\
\hline \multicolumn{2}{|c|}{ Movimento Unificado de Favelas, Cortiços e Promorar (MNRU) } \\
\hline \multicolumn{2}{|c|}{ Centro do Trabalhador para Defesa da Terra 'Paulo Canarim' (MNRU) } \\
\hline \multicolumn{2}{|c|}{ Associação dos Usuários dos Transportes Coletivos do Estado de São Paulo (MNRU) } \\
\hline \multicolumn{2}{|c|}{ Movimento dos Sem-Terra (MNRU) } \\
\hline \multicolumn{2}{|c|}{ Federação das Associações de Moradores do Rio de Janeiro (MNRU) } \\
\hline \multicolumn{2}{|c|}{ Associação dos Inquilinos da Ceilândia (MNRU) } \\
\hline
\end{tabular}

Confederação Nacional das Associações de Moradores (CONAM)

Federação das Associações de Moradores do Estado do Piquí (FAMEPI)
Apresentou uma pauta extensa, com 24 pontos que incluíam o direito à moradia pelos trabalhadores assalariados, que o custo de moradia não ultrapassasse $20 \%$ do salário do trabalhador, dimensões mínimas das unidades, criação de um Fundo Municipal de Habitação, garantir 15\% do orçamento da União para o investimento em moradia, investir em pesquisa e qualidade para reduzir os custos da unidade e melhorar o produto oferecido pelos programas habitacionais, adotar mecanismos restritivos do direito de propriedade como o IPTU progressivo e a desapropriação, urbanização de favelas, gestão participativa e ainda uma política de transporte público com subsídios e isenções

Defendeu uma proposta com onze pontos que incluíam o direito universal à moradia digna, a gestão participativa, o adensamento nas áreas urbanas já dotadas de infraestruturas, moradias próximas ao centro, desapropriação de terrenos ociosos, redução da prestação da casa própria ao preço de custo, dotação orçamentária de $15 \%$ para o investimento em habitação, IPTU progressivo, transporte público subsidiado, gestão participativa nas políticas urbanas e de transportes

Fonte: Elaborada pelos autores.

\section{O setor privado no centro de uma nova política habitacional}

Além da política urbana, a política habitacional foi objeto de amplo debate na Subcomissão. Na segunda reunião, os constituintes abordaram a importância das funções desempenhadas pelo Banco Nacional de 
Habitação (BNH), que havia sido extinto no ano anterior, em 1986. A Constituinte Myriam Portella (PDS) perguntou diretamente aos representantes dos arquitetos qual a opinião deles sobre o tema da habitação (Brasil, 1987c, p. 32).

Conforme exposto por Myriam nessa reunião, havia uma preocupação generalizada em como responder à demanda por casas populares na ausência do BNH. Esse tema retornaria à pauta e ocuparia grande parte dos debates da décima segunda e décima terceira reunião. Entretanto, já naquela época era sabido que a população de baixa renda assistida pelas iniciativas do BNH estava abaixo da média populacional em relação à produção geral de unidades promovidas pelo Banco. Esse quadro agravou-se a partir de 1971, quando o banco passou a atuar como banco de segunda linha, por meio das Companhias de Habitação, e priorizou as faixas de habitação de mercado e os programas de lotes urbanizados, preocupando-se mais com o retorno do capital investido e fazendo com que a habitação para as classes mais baixas tivesse uma participação ainda menor na atuação do banco (Bolaffi, 1977; Santos, 1999; Cariello Filho, 2011).

A exposição de Fábio Goldman, então membro titular do Conselho Superior do Instituto de Arquitetos do Brasil na gestão de 1986-87, expressa o conteúdo dessa crítica que foi a mais difundida entre os setores técnicos especializados. Fábio Goldman e, posteriormente, Telmo Borba Magadan, então presidente da Empresa Brasileira de Transporte Urbano (EBTU), acusavam o BNH de praticar uma política urbana estritamente financeira (Brasil, 1987c, p. 32 a 37).

O BNH foi criado em agosto de 1964, com o objetivo de ampliar a produção da habitação e das infraestruturas necessárias para a urbanização brasileira. Produziu 4,5 milhões de unidades em vinte e dois anos de atuação. Em certo sentido, a resposta do Banco articulou ao problema habitacional o problema social e a questão da moradia na dimensão urbana. Ao mesmo tempo, ao não colocar limites à propriedade privada do solo urbano e à transferência de riquezas para o setor privado, derivado dos investimentos públicos realizados na cidade, permitiu que o Banco funcionasse na contramão de uma política habitacional integrada ao direito à cidade, principal bandeira da política urbana defendida por ambos os arquitetos em seus pronunciamentos.

Outra posição apresenta-se na décima terceira reunião na fala do Constituinte Ricardo Izar (PFL), que defendia uma dotação orçamentária específica para a habitação, como aliás também defenderiam as entidades ligadas às associações dos inquilinos. Izar apresenta o déficit de moradias, apontando como solução uma dotação orçamentária para os programas de moradia como elemento central da política habitacional. Posteriormente, os mecanismos de financiamento da moradia foram incluídos nos Relatórios da Subcomissão (Brasil, 1987h, p. 60).

Nesse sentido, a necessidade de suprir as funções do BNH e prover políticas de financiamento para a produção de moradia ganhava uma funcionalidade no acordo entre o problema social e os interesses em jogo sob o novo pacto social. Isso permitia atrelar o problema (déficit) à solução (financiamento), incluindo o setor privado da indústria da construção civil, no centro de um programa de fomento de uma nova política habitacional.

Na mesma reunião também foi ouvido Paulo André Jorge Germanos, Representante do Sindicato das Empresas de Compra, Venda, Locação e Administração de Imóveis de São Paulo que, em pronunciamento anterior, defendeu a oferta em massa de habitação para locação com investimentos do setor privado (Brasil, 1987h, p. 48).

A exposição de Germanos expressava os interesses de um conjunto de grandes proprietários urbanos e, embora demonstrasse amplo conhecimento do setor de aluguéis, não admitia uma política de aluguéis mediada pelo estado, o que reduziria a renda dos investimentos privados no setor. Pela indústria da construção, Moacyr Gomes de Almeida manifesta logo em seguida o interesse em uma política pública de desenvolvimento urbano, como foi o $\mathrm{BNH}$, com o propósito não apenas de atender à demanda habitacional, mas também de "melhorar a situação dos investimentos para locação" (Brasil, 1987h, p. 51).

Para Almeida não existia um conflito de interesses de classe na definição da função social da propriedade. 
Eu sugiro que não façamos essa distinção e que tudo seja social. Nós temos um sistema capitalista de objetivo social, então tudo é social. Vamos utilizar isso e não tentar distinguir como se fosse um conflito que não há na verdade (Brasil, 1987h, p. 67).

A operação ideológica permitiria ao Estado legitimar em um novo acordo as práticas acumulativas, com vantagem para os setores imobiliários e da construção civil através do atendimento da demanda dos setores de baixa renda, justificando assim os mecanismos de financiamento da moradia, a defesa da moradia digna e da função social da propriedade, incluídos no "Anteprojeto da Subcomissão".

Durante a décima terceira reunião, os participantes representando os setores da indústria da construção e do mercado imobiliário expuseram as suas interpretações da função social da propriedade, essas definições refletem os seus interesses materiais e os seus posicionamentos ideológicos no debate sobre a cidade. Para esses setores, a ausência de um conflito de interesses de classe permitiria legitimar, no âmbito do Estado democrático, suas práticas econômicas acumulativas. Desse modo, disputavam com os setores técnicos e burocráticos a definição da função social da propriedade e o controle dos mecanismos redistributivos presentes no projeto de lei de 1983.

\section{Conclusões}

A Reforma Urbana costuma ser apresentada como a pauta reivindicatória dos movimentos sociais urbanos. Isso porque os instrumentos de restrição ao direito de propriedade como o IPTU progressivo, o Parcelamento e edificação compulsórios e a desapropriação mediante títulos da dívida pública, que foram incluídos no capítulo da política urbana da Constituição de 1988, através da Emenda Popular n. 63, que dispõe sobre a Reforma Urbana. Essa emenda popular foi o resultado político de um pacto popular democrático para as cidades, que aglutinou setores sociais diversos, os setores técnicos que participavam do estado, a academia e os movimentos sociais urbanos.

Pouco se aborda que no plano concreto a Reforma Urbana também fez parte das propostas elaboradas por setores técnicos, estes que participaram do governo no período civil-miliar. O PL 775 foi proposto em 1983 e incluiu os principais instrumentos da Reforma Urbana, cujo teor foi fortemente criticado pelos representantes do mercado imobiliário e da indústria da construção na época. O PL 775 e seus instrumentos foram evocados logo na segunda reunião da Subcomissão. Na décima terceira reunião estiveram presentes os representantes do mercado imobiliário e da indústria da construção civil, principais críticos ao projeto de Reforma Urbana do período civil-militar que reiteraram suas críticas aos instrumentos da Reforma Urbana, reapresentados no período da redemocratização.

0 "Anteprojeto da Subcomissão" afirmou o direito à moradia digna, incluiu mecanismos de financiamento habitacional, reconheceu a função social da propriedade e os instrumentos da desapropriação e da usucapião, mas evitou incluir os mecanismos mais polêmicos. Esses instrumentos de restrição ao direito de propriedade fizeram parte do PL 775 e das propostas apresentadas na Subcomissão da Questão Urbana e dos Transportes por várias instituições, como a Comissão Nacional de Desenvolvimento Urbano (CNDU), o Instituto Nacional de Arquitetos (IAB), a Federação Nacional de Arquitetos (FNA) e a Associação Brasileira de Escolas de Arquitetura (Asbea). Foi somente na décima quinta reunião que os representantes dos movimentos sociais urbanos foram ouvidos, articulados no Movimento Nacional pela Reforma Urbana - que combinava setores populares, técnicos e acadêmicos - e nas Associações de Inquilinos. As propostas apresentadas por eles na décima quinta reunião também incluía os instrumentos da Reforma Urbana.

O debate sobre a política urbana encontrado nas atas da subcomissão demonstra a diversidade de interesses em disputa. 0 arranjo político expresso no Anteprojeto da Subcomissão atesta um compromisso com os setores liberais que operam a dimensão material da questão urbana. A prática desses setores redefine o sentido do desenvolvimento urbano e expressa a estreita vinculação da produção da cidade real com os acordos sociais que produziram o Anteprojeto da Subcomissão. Sendo assim, torna-se ainda mais 
evidente a dificuldade enfrentada pelos municípios para implementar uma política urbana redistributiva do direto à cidade através dos instrumentos da Reforma Urbana.

\section{Referências}

Bassul, J. R. (2002). Reforma urbana e Estatuto da Cidade. EURE (Santiago), 28(84), 133-144. https://dx.doi.org/10.4067/S025071612002008400008.

Bolaffi, G. (1977). A casa das ilusões perdidas: aspectos socioeconômicos do plano nacional de habitação. Caderno CEBRAP, 27, 1-29.

Bonduki, N. G., \& Koury, A. P. (2010). Das reformas de base ao BNH: as propostas do seminário de habitação e reforma urbana. Arquitextos, 10(120.02). Recuperado em 14 de novembro de 2020, de http://www.vitruvius.com.br/revistas/read/arquitextos/10.120/3432.

Bonduki, N. G. (2018). A Luta pela Reforma Urbana no Brasil (1ạ. ed.). São Paulo: Instituto Casa da Cidade. 244 p.

Brasil (1983, 6 de maio). Projeto de Lei n. 775, de 06 de maio de 1983. Dispõe sobre os objetivos e a promoção do desenvolvimento urbano e dá outras providências. Brasília: Diário do Congresso Nacional, seção 1, 2831-2834.

Brasil (1987a, 20 de março). Projeto de resolução no. 2-C, de 20 de março de 1987. Dispõe sobre o regimento interno da Assembleia Nacional Constituinte. Brasília: Diário da Assembleia Nacional Constituinte, Ano I, n. 31, 833-840.

Brasil (1987b, 1 de maio). Ata da reunião de instalação e Ata da primeira reunião ordinária da Subcomissão da Questão Urbana e Transportes. Brasília: Diário da Assembleia Nacional Constituinte, Ano I n. 53 (Suplemento), 164-167.

Brasil (1987c, 16 de julho). Atas da segunda, terceira e quarta reunião ordinária da Subcomissão da Questão Urbana e Transportes. Brasília: Diário da Assembleia Nacional Constituinte, Ano I, n. 95 (Suplemento), 26-59.

Brasil (1987d, 18 de julho). Ata da sexta reunião ordinária da Subcomissão da Questão Urbana e Transportes. Brasília: Diário da Assembleia Nacional Constituinte, Ano I, n. 97 (Suplemento), 67-80.

Brasil (1987e, 19 de julho). Ata da sétima reunião ordinária da Subcomissão da Questão Urbana e Transportes. Brasília: Diário da Assembleia Nacional Constituinte, Ano I, n. 98 (Suplemento), 53-60.

Brasil (1987f, 20 de julho). Ata da oitava reunião ordinária da Subcomissão da Questão Urbana e Transportes. Brasília: Diário da Assembleia Nacional Constituinte, Ano I, n. 99 (Suplemento), 107-126.

Brasil (1987g, 21 de julho). Atas da nona, décima e décima primeira reunião ordinária da Subcomissão da Questão Urbana e Transportes. Brasília: Diário da Assembleia Nacional Constituinte, Ano I, n. 100 (Suplemento), 113-163.

Brasil. (1987h, 22 de julho). Atas da décima segunda e décima terceira reunião ordinária da Subcomissão da Questão Urbana e Transportes. Brasília: Diário da Assembleia Nacional Constituinte, Ano I, n. 101 (Suplemento) p. 28-70.

Brasil (1987i, 23 de julho). Atas da décima quarta e décima quinta reunião ordinária da Subcomissão da Questão Urbana e Transportes. Brasília: Diário da Assembleia Nacional Constituinte, Ano I, n. 102 (Suplemento), 87-107.

Brasil (1987j, 24 de julho). Atas da décima sexta à vigésima reunião ordinária da Subcomissão da Questão Urbana e Transportes. Brasília: Diário da Assembleia Nacional Constituinte, Ano I, n. 103 (Suplemento), 125-150.

Brasil (1987k, 25 de julho). Atas da vigésima primeira reunião (extraordinária) da Subcomissão da Questão Urbana e Transportes. Brasília: Diário da Assembleia Nacional Constituinte, Ano I, n. 104 (Suplemento), 104-126.

Brasil (1988a, 5 de janeiro). Assembleia Nacional Constituinte Vol. 258, Emendas Populares. Brasília: Senado Federal: Centro Gráfico.

Brasil (1988b, 5 de outubro). Constituição da República Federativa do Brasil de 5 de outubro de 1988. Brasília: Diário Oficial da União. Recuperado em 14 de novembro de 2020, de https://www2.camara.leg.br/legin/fed/consti/1988/constituicao1988-5-outubro-1988-322142-publicacaooriginal-1-pl.html.

Brasil (2001, 11 de julho). Lei n. 10.257, de 10 de julho de 2001. Regulamenta os Arts. 182 e 183 da Constituição Federal, estabelece diretrizes gerais da política urbana e dá outras providências. Brasília: Diário Oficial da União, seção 1.

Câmara dos Deputados (1987). Subcomissão da Questão Urbana e Transporte. Atas das reuniões. Recuperado em 27 dezembro de 2019, de https://www2.camara.leg.br/atividade-

legislativa/legislacao/Constituicoes_Brasileiras/constituicao-cidada/o-processo-constituinte/comissoes-e-

subcomissoes/comissao6/subcomissao6b 
Cardoso, A. L. (1997). Reforma urbana e planos diretores: avaliação da experiência recente. Cadernos IPPUR, 16(1). Recuperado em 14 de novembro de 2020, de https://revistas.ufrj.br/index.php/ippur/issue/viewFile/273/82

Cariello Filho, O. (2011). As políticas federais de habitação no Brasil (1964 a 2002) e a reprodução da carência e da escassez da moradia dos trabalhadores (Tese de doutorado). Faculdade de Arquitetura e Urbanismo, Universidade de Brasília, Brasília.

Francisconi, J. G. (2013). Seminário de Quitandinha e Q+50: resultado, avaliação e desafios atuais. Arquitextos, 14(160.04). Recuperado em 14 de novembro de 2020, de https://www.vitruvius.com.br/revistas/read/arquitextos/14.160/4880.

Grazia, G. (2002). Estatuto da Cidade: uma longa história com vitórias e derrotas. In Ozorio, L. M. (Org.), Estatuto da Cidade e Reforma Urbana: Novas perspectivas para as cidades brasileiras. Porto Alegre: Sérgio Fabris Editor.

Jacobi, P. (1989). Movimentos Sociais e Políticas Públicas: Demandas por saneamento básico e saúde. São Paulo 1974-1984 (2a ed.). São Paulo: Cortez Editora.

Koury, A. P. (2013). A política urbana e a questão social: Quitandinha, o que restou? Arquitextos, 14(159.03). Recuperado em 14 de novembro de 2020, de http://www.vitruvius.com.br/revistas/read/arquitextos/14.159/4846.

Kowarick, L., \& Brant, V. C. (1976). São Paulo 1975 Crescimento e Pobreza (1ạ. ed). São Paulo: Edições Loyola.

Kowarick, L. (1988). As lutas sociais e a cidade. São Paulo: passado e presente (1ª. ed.) . São Paulo: Editora Paz e Terra.

Maricato, E. (2014). O Impasse da política urbana no Brasil (3ํae ed). Rio de Janeiro: Vozes.

Quinto Jr., L. P. (2003). Nova legislação urbana e os velhos fantasmas. Estud. av., 17(47), 187-196.

Rolnik, R. (1994). Planejamento urbano nos anos 90 novas perspectivas para velhos temas. In Ribeiro, L. C. Q., \& Santos Jr., O. (Eds.), Globalização, fragmentação e reforma urbana. Rio de Janeiro: Civilização Brasileira.

Santagada, S. (1990). A situação social no Brasil nos anos 80. Indicadores Econômicos, 17(4), 121-143.

Santos, C. H. M. (1999). Políticas federais de habitação no Brasil: 1964/1998. Texto para discussão no 654. Brasília: Instituto de Pesquisa Econômica Aplicada (IPEA).

Santos, C. N. F. (1981). Movimentos urbanos no Rio de Janeiro (1ํ. ed). Rio de Janeiro: Zahar Editores.

Editor: Rodrigo Firmino

Recebido: 08 jan. 2020

Aprovado: 11 set. 2020 